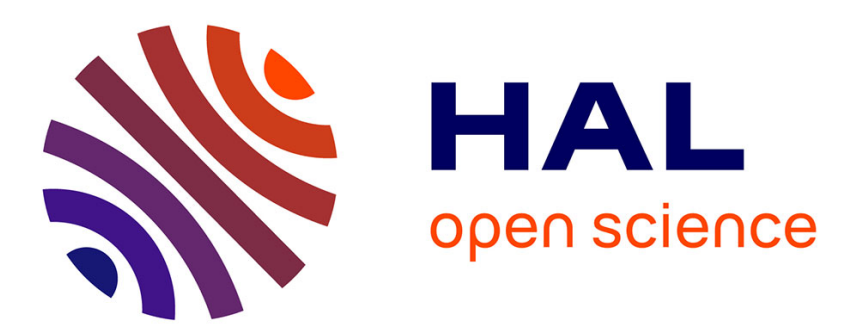

\title{
Exploring How Individuals Manage Their Image When Interacting with Professional Contacts Online
}

\author{
Aparna Gonibeed, M. N. Ravishankar
}

\section{To cite this version:}

Aparna Gonibeed, M. N. Ravishankar. Exploring How Individuals Manage Their Image When Interacting with Professional Contacts Online. 15th Conference on e-Business, e-Services and e-Society (I3E), Sep 2016, Swansea, United Kingdom. pp.401-410, 10.1007/978-3-319-45234-0_36 . hal01702192

\section{HAL Id: hal-01702192 \\ https://hal.inria.fr/hal-01702192}

Submitted on 6 Feb 2018

HAL is a multi-disciplinary open access archive for the deposit and dissemination of scientific research documents, whether they are published or not. The documents may come from teaching and research institutions in France or abroad, or from public or private research centers.
L'archive ouverte pluridisciplinaire HAL, est destinée au dépôt et à la diffusion de documents scientifiques de niveau recherche, publiés ou non, émanant des établissements d'enseignement et de recherche français ou étrangers, des laboratoires publics ou privés. 


\title{
Exploring How Individuals Manage Their Image When Interacting With Professional Contacts Online
}

\author{
Aparna Gonibeed ${ }^{1}$, Ravishankar, M.N. ${ }^{1.1}$ \\ ${ }^{1}$ Liverpool Hope University, Liverpool, United Kingdom \\ ${ }^{1.1}$ Loughborough University, Loughborough, United Kingdom \\ gonibea@hope.ac.uk; m.n.ravishankar@lboro.ac.uk
}

\begin{abstract}
Social media is ubiquitous and most professionals feel compelled to use it for both personal and professional purposes. Although interacting with workplace colleagues and managers across online-offline and work-life offers several advantages, it also poses several image related challenges. This study aims to assess how individuals manage their image when interacting with professional contacts online. The article does this by studying individuals' experiences of interacting online and their responses to cope with emerging conflicts. For this purpose, 31 interviews were conducted among Indian IT professionals. The findings suggest that respondents exercised audience segregation and content segregation to convey a desired professional image. By focusing on the impact of interactions with professional contacts online, the study suggests that individuals enact a 'Restricted Self' online. In doing so, the article contributes to the literature on online impression management.
\end{abstract}

Keywords: impression management, social media, cognitive demands.

\section{Introduction}

Most employees now interact on social media. In these interactions, they must be cautious as image plays a vital role in gaining respect and liking from workplace colleagues. Hence, impression management is inevitable when interacting with professional contacts online. Within the wider literature on managing image online, it is seen that individuals tend to create a persona that closely relates to their offline selves. In other words, individuals try to maintain integrity between their online-offline selves and strive for accuracy with their offline and 'true' self [32]. However, given that individuals pursue diverse impression goals across work-life [8], they may experience some image related concerns. For instance, as employees increasingly socialize online, professional contacts may compare interactions across work-life and online-offline settings and express doubts on the validity of the information presented. Additionally, such comparisons may lead professional contacts to alter the image they have already constructed. Here, negative re-construction of an image by professional contacts may have 
adverse effects on respect and liking at the workplace. Consequently, the nature of interactions online is considerably changing as individuals use reflexivity and manage an image by using a variety of online boundary management strategies [17].

The dilemma outlined above influences the questions: How do individuals manage their image when they interact with professional contacts online? And given the risk of reputation loss, why do individuals interact with professional contacts online? To address this question, we conducted an in-depth qualitative study on Indian IT professionals and draw on extant scholarship on impression management to analyze the data.

The findings indicate that individuals exercise restraint in their interactions on social media. They do this by exercising two boundary management strategies: audience segregation and content segregation. Consequently, they enact a 'Restricted Self' or a restricted version of the self to protect their professional image. The article is organized as follows. First, we review the literatures on impression demands due to social media and appropriate coping strategies. Next, we describe research methods and discuss findings of the study. Finally, we examine the notion of 'Restricted Self' and discuss the implications of interacting with professional contacts online.

\section{Background}

People generate particular images of the self and thereby influence how others perceive and treat them. At the workplace, image plays a vital role and has important consequences for career progression and achievement of status and power [6], [10], [23]. Consequently, individuals spend considerable time at the workplace to convey a desired image that represents desirable qualities (e.g. intelligence, humor, initiative, trustworthiness) and elicit approval from key members [7, 8].

\subsection{Challenges of online impression management}

In the modern workplace, individuals must rely on their interactions (for e.g. profile, status, photos) on social media to convey a desired professional image [9], [18]. Broadly speaking, impression strategies to convey an image via social media are characterized by the extent of accuracy of information that individuals share from their offline settings in their online interactions, also referred to as representativeness [30, 31]. By being representative in their interactions on social media, individuals wish to convey an image of the 'real', 'true' and 'authentic' self. However, when employees share 'real' and 'authentic' selves on social media and interact or socialize online, they face two impression related conflicts. One, online interactions may be viewed in the absence of any context thus opening up opportunities for misinterpretations by the audience [26], [28]. In such instances, it is important to note that while favourable stereotypes of professional competence and character can enhance one's image, unfavourable stereotypes detract from one's image. Additionally, individuals may find it challenging to correct unfavourable stereotypes arising from misinterpretations based on their selfpresentations on social media [17]. Two, individuals tend to exercise 'region-behaviour'; different behaviours when with different kinds of audience [8]. As individuals 
pursue diverse image goals across work-life, they exhibit various aspects of their personality depending on the goal. However, such region-behaviour becomes meaningless as social media bridges work-life image and online-offline boundaries. Hence, employees risk loss of reputation, professional image and blurring of boundaries when employees view their colleagues exhibiting inappropriate behaviour on social media [17], [24]. Such instances have a direct and immediate negative impact on how individuals are perceived by colleagues at the workplace. Given these challenges to impression management online, the question of how do individuals manage their image online is a pertinent inquiry.

\section{$2.2 \quad$ Coping strategies}

Existing literature suggests that employees cope with the above impression related challenges by choosing between strategies that apparently lay on a continuum. At one end of the continuum, scholars [14], [25] suggest that individuals exercise various online boundary management strategies and present a 'Restricted self' by exercising self-censorship and adjusting profile visibility. Some studies support this argument by suggesting individuals customize profiles to disclose different information to different individuals or create multiple profiles [13] [31, 32]. In this manner, scholars suggest that individuals seek control over their professional image by controlling the audience to their interactions and exercising caution in their status updates. Alternatively, on the other end of the continuum, few scholars [20], [33] argue that individuals are 'cyborgs' or 'hybrid selves' and integrate their online-offline self. In this notion of entanglement, individuals view their image as a set of characteristics that combine their physical and virtual identity into one image. In some ways, this hybrid self is similar to disembodied or dual selves, as the cyborgian self is fluid, malleable and occasionally, multiple. Although emerging literature pays attention to explanations that lay outside of the continuum [17], [24], we know little about how employees cope with impression demands online. This is important to understand because social media has a growing presence at the workplace. The remainder of this article describes the study that was conducted and the findings that emerged.

\section{Research Method}

In this study, we explored how a group of Indian IT professionals experience and respond to interacting with professional contacts on social media. To do this we adopted an interpretivist viewpoint which "does not predefine dependent and independent variables but focuses on the complexity of human sense-making as the situation emerges" [12]. From this viewpoint, the same physical institution, artefact or human action can have different meanings for different human subjects as well as the observing social scientist [15]. In this process, the researcher gets involved with the respondents in the process of negotiating meaning and research is inevitably influenced by the values of the researcher [2], [16]. 


\subsection{Research Context}

The Indian IT industry competes on a global level and provides employment opportunities in large numbers to graduates [5], [19]. In terms of IT-work, broadly three categories are identified: software solutions, products and services; the term 'IT professionals' refers to all those individuals employed by the IT-industry. The current IT professional workforce consists of software engineers and other non-engineering graduates who are educated, well paid, mobile and closely linked into the global services economy, whether working in India or abroad [29]. IT remains a viable career choice for many educated Indians today, for whom it offers competitive salaries compared to other sectors as well as an opportunity to live and work outside of India [29]. Within the wider literature, the IT workplace is associated with power imbalances and IT professionals are viewed within a post-colonial context aspiring a bourgeois lifestyle [1], $[3,4],[20]$.

\subsection{Sample}

This study is based on data collected from qualitative interviews with 31 Indian IT professionals who had a graduate degree or above. The sampling approach adopted in this study was non-probability using purposive and snowball sampling techniques. Non-probability sampling refers to sampling without random selection methods [11]. Purposive sampling is when a researcher targets a specific subset of people who meet the exact criteria of respondents or target group. In this case, the research targeted a sub-group: Indian IT professionals. Next, snowball sampling techniques were used; that is, respondents recommended their friends to the researcher and assisted the researcher in marketing the study on popular social networking sites like Facebook and Twitter. Further, ad-hoc quota system was followed to eliminate gender bias in the sample. Within this category, we sought to include in the study IT professionals from multinational companies (MNC) and Indian IT companies (focused on software IT companies) so that the results can be generalized to the occupational group of respondents. In addition to interviews, field notes were produced in the process. Table 1 summarizes the interviews with respondents across various forms of IT companies by grouping them into four basic categories: Manager (greater than ten years experience), Program Analyst (between 7 to 10 years experience), Associate-Projects (between 3 to 7 years experience) and Human Resource Manager ( 5 years experience). 
Table 1. Interviews and role of respondents

\begin{tabular}{|c|c|c|}
\hline Group & Role of respondents & No. of interviews \\
\hline 1 & Managers & 12 \\
\hline 2 & Program Analyst & 9 \\
\hline 3 & Associate - Projects & 8 \\
\hline 4 & $\begin{array}{c}\text { Human Resource Manag- } \\
\text { ers }\end{array}$ & 2 \\
\hline
\end{tabular}

During interviews that lasted an hour on average, in response to questions like: "Would you say you are concerned about how a recruiter in the future may look at all your interactions on twitter before hiring you?" and "Have you experienced any conflicts at work by adding or not adding contacts from the office?" respondents spoke at length about their experiences of interacting on social media with colleagues, clients and other professional colleagues. They also reflected on potential consequences for their careers, respect and liking by workplace colleagues and such impact on their image at the workplace. Further, respondents spoke about anxieties, fears and cognitive demands when interacting online. Of noteworthy mention is that managerial interference was noted as a predominant issue among respondents which exacerbated their anxiety when interacting with professional contacts on Facebook.

\subsection{Data Analysis}

The interviews were transcribed; the length of the transcript accurately reflects the respondents' experience in identifying suitable coping strategies. Data analysis was an on-going and iterative process through the data collection period. Through such a process, we achieved theoretical saturation; that is, no additional themes emerged with additional data [2]. In the first step of data analysis, we used principles of grounded theory [27] to analyze the data. In this phase, we used sentence analysis to look for the major idea in each sentence, open coding to group the concepts into categories and axial coding [27], whereby we searched for the relationships between the sub-categories at a conceptual level and categorized them into higher-order themes (represented in Table 2). This process facilitated quick reference to similar concepts and their representative examples that could be collapsed into fewer categories and themes. Finally, we looked for relationships across the themes through an iteration process between emerging data 
and existing literature to determine possible explanations. Such an eclectic approach to the data helped to clarify the dynamics associated with impression management theory and how individuals respond to the conflicts that arose.

Table 2: Theme illustrations

\begin{tabular}{|c|c|}
\hline $\begin{array}{l}\text { First-order } \\
\text { categories }\end{array}$ & Exemplary quotes \\
\hline $\begin{array}{l}\text { Theme I } \\
\text { (second-or- } \\
\text { der): } \\
\text { Audience } \\
\text { segregation }\end{array}$ & $\begin{array}{l}\text { You don't want that if you put a status message, it should be shown to every- } \\
\text { one. People perceive things in a different way, right. They see your pictures, and } \\
\text { they may not always know the context right. A lot of the cultural associations } \\
\text { would be lost. A lot of the cultural contexts would be lost. So the entire infor- } \\
\text { mation is not being conveyed, all they can see is maybe a photograph (AN, 30) } \\
\text { I'm very close to the team that I work with and it's easy for the lines to blur. } \\
\text { But at the end of the day my boss is my boss and my colleague is still somebody } \\
\text { that I have to go to work with and I maybe I'm just cautious. I haven't had a bad } \\
\text { experience or anything, but I prefer to make sure the lines don't gel (AR, 25) }\end{array}$ \\
\hline $\begin{array}{l}\text { Theme II: } \\
\text { Content } \\
\text { segregation }\end{array}$ & $\begin{array}{l}\text { The process of writing a blog is a search for your identity. I have a private blog } \\
\text { that I keep. Even if someone finds out everything about it, I'm not afraid that it's } \\
\text { there. It's just that I chose to not make it public. The process of blogging will } \\
\text { reveal things to you that you did not know and it will help for yourself and others } \\
\text { (SA, 39) } \\
\text { One thing I realized is that Twitter for instance is a tool for others to understand } \\
\text { about you as a personality. I'm very conscious about that. So I use Twitter as a } \\
\text { way to express my opinion in a way that reflects my personality or reflect my } \\
\text { knowledge about something or reflect my opinion, through which people under- } \\
\text { stand who I am (RA, 36) }\end{array}$ \\
\hline
\end{tabular}

\section{$4 \quad$ Findings}

The data and analyses demonstrate that individuals take caution while building profiles and accepting friendship requests online due to concerns related to impression management. Broadly, respondents managed impressions online by audience segregation and content segregation. We discuss these findings in this section.

\subsection{Audience Segregation}

Consistent with previous findings, the respondents in this sample exercised various online boundary management strategies to segregate their online audience [14], [25], [32]. In analyzing the data, we focused on why respondents attached significance to audience segregation. At first sight, it appeared that respondents segregated among professional contacts in order to avoid socially awkward situations at the workplace, however, a deeper analysis suggests that respondents sought symbolic rewards in the form 
of liking and respect. Additionally, respondents also used these interactions to convey a desired image. For instance, SA explains that he uses his interactions on social media to convey an image of a multidimensional self:

A bunch of folks think of me as the uber engineer, while others think I am a Marketer and one doesn't necessarily link me to the other. On Facebook page or LinkedIn network, they get to know who I am, so that's a way of getting a feel for the bigger person and a composite personality (SA, 39)

Another respondent explains that adding a professional contact to her network increases her likeability and makes it easy to approach the professional contact for any workrelated favors in the future:

You add people because it is an additional glimpse of you that they can see apart from what you already told them and as long as they are in your network it is an easier way to reach out to them if you need something (AI, Female, 32).

In addition to various online boundary management strategies, respondents were cautious of the audience at the workplace as well. In other words, respondents were keen to ensure that they were not 'caught' interacting online at the workplace as this had immediate negative implications on their professional image. For instance, NA explains how interacting at the workplace had implications on his professional image and performance rating:

I have lot of friends in the company so I used to chat and although I did my work, my manager never liked it. He would see communicator windows popping and me chatting at the workplace. He raised it many times and did not like me for that. There were (performance) rating issues and I had to bear it. It is an image which I had made up. (NA, Male, 30)

Overall, these experiences make them cautious when interacting online especially with professional contacts. In response, respondents appear to use a variety of online boundary management strategies which appear to alleviate impression demands.

\subsection{Content Segregation}

Misinterpretations by professional contacts signals failed impression management efforts and exacerbates impression demands. Almost all respondents feared consequences like loss of respect and liking by professional contacts. However, some ( $40 \%$ of the sample) felt particularly threatened by it. This was because some respondents experienced some form of negative experiences that shaped their responses. For instance, online messages on public forums by managers like "Don't you have some work to do?" were specific incidents that triggered changes in how respondents interacted online. One respondent explains an incident that impacted him considerably was when he was told he may be fired as he openly commented on a company policy online:

I voiced my opinion against one of the policies that affected my training batchmate and myself. So we were called directly and asked, "You don't want to lose your job, do you?" I was only 6 months into the job and I really got scared at that time. So after that, I changed the way I wrote my mails you know and started talking to the right people and not talking to everybody in the world (GA, 31) 
In this sense, although the strategy altered slightly, the general response was still the same. Some respondents took particular steps like avoiding oversharing personal information online and reinforcing work-life boundaries. For example, many respondents said "I might enjoy that privately but exercise caution online" and "It is about maintaining your image, you are giving them an opportunity to find out something about you"; thus, expressing awareness of consciously using social media to build an image for professional contacts.

Although a handful of respondents claim that they exercise full disclosure by synchronizing their interactions across all social media sites, they did not share any personal information online. For instance, one respondent said, "Although I share information openly across public networking sites, I do not discuss family or other things." Similarly, another respondent said that his accounts are linked and he accepts all professional contacts on any social network, however, he does not share personal information publicly:

All my bosses are on my social network. My Twitter feed, LinkedIn and Facebook pages are connected. But, I also have a private blog where I write everything and I chose to not make it public. Even my wife cannot see the blog. (SA, 39).

The respondents perceive that social media inevitably blurs work-life image and the further notion that interactions on the internet are permanent forced them to exercise caution.

In the process, respondents attach significance to their interactions online and invest considerable time and effort in impression management related activities. Respondents who exercised strategic disclosure responded to negative experiences by establishing various forms of self-censorship to alleviate impression demands.

\section{Discussion}

Motivated by recent research on online impression management [27], [24], this study set out to explore how individuals manage their image when interacting with professional contacts online. The empirical data presented above provides us with a deeper and alternative understanding of how individuals manage image online. It also vividly documents the rewards and conflicts that impact how individuals respond to impression related conflicts. This study supports literature that suggests that individuals are representative in their interactions online and extends a broader theoretical understanding of individuals' interactions online.

\subsection{Restricted Self}

In response to impression demands arising from impression management online, respondents chose to exercise control over their professional image by continually evaluating their boundary management strategies and exercising reflexivity. The data offers insights as to why respondents exercised control on professional image. One, respondents perceive the workplace audience to be in a powerful position. Since the workplace 
audience constitutes the 'key audience' in regard to professional image [6], [10], [21], respondents sought control over how they were perceived by restricting their interactions on social media. Additionally, power imbalances are popularly associated with the research setting of Indian IT professionals [4], [21, 22]. As evident in the data, the respondents are aware of such power imbalances and use social media to reinforce the same. Second, respondents pursue diverse impression goals in their work-life, consequently, as a boundary management strategy, respondents restrict their interactions online. This is evident in the data when respondents accept professional contacts to increase likability and respect yet use online boundary management strategies to control what their professional contacts can see online. Finally, when interacting with professional contacts online, respondents realize how visible they are in the offline setting. Previous research [17], [25] suggests that individuals seldom perceive the social consequences of their interactions on the internet. This is evident in the data when some respondents critically evaluate their interactions online to prevent any negative stereotypes that may arise in the future.

It is important to note that individuals enact a 'Restricted Self' because they fear consequences like loss of respect and liking by professional contacts. Further, the asynchronous and asymmetric movement across online-offline settings made them particularly aware of their diverse work-life image and helped them decide how to manage their professional image.

\section{Conclusion}

In any workplace, impression management serves many purposes and individuals experience cognitive demands while managing a professional image. In addition to the vivid differences in work-life impression goals, the respondents in this study experienced heightened impression demands when interacting with professional contacts online due to complex power asymmetries and fear of negative social consequences and stereotypes arising from interacting with professional contacts on social media. They coped with these demands by choosing between strategies to control the audience to their interactions (audience segregation) and controlling the content of their interactions (content segregation) online. Consequently, it appears that the respondents are in part representative or 'real' and practicing 'region-behavior' for the workplace audience by enacting a 'Restricted Self'. Of particular significance in this study is that despite the cognitive demands which inevitably lead to scrutinizing strategies that take up a significant portion of their time, the respondents find a way to interact online.

Overall, this study adds to the growing literatures on interacting with professional contacts online. It provides an alternative explanation on how employees resolve conflicts arising from interacting with professional contacts online. The findings have implications for similar occupational groups across geographies. 


\section{References}

1. Brosius, C., 2010. India's Middle Class: New forms of urban leisure, consumption and prosperity, New Delhi: Routledge.

2. Corbin, J. \& Strauss, A., 1990. Grounded theory research: Procedures, canons, and evaluative criteria. Qualitative sociology, 13(1), pp.3-21.

3. D’Mello, M. \& Eriksen, T., 2010. Software, sports day and sheera: Culture and identity processes within a global software organization in India. Information and Organization, 20(2), pp.81-110.

4. Fernandes, L., 2000. Nationalizing 'the global': Media images, cultural politics and the middle class in India. Media, Culture \& Society, 22(5), pp.611-628.

5. Friedman, T., 2005. The world is flat, London: Penguin Books.

6. Gardner, W. \& Martinko, M., 1988a. Impression management in organizations. Journal of Management, 14(2), pp.321-339.

7. Giacalone, R. \& Rosenfeld, P., 1986. Self-presentation and self-promotion in an organizational setting. The Journal of social psychology, 126(3), pp.321-326.

8. Goffman, E., 1959. The presentation of self in everyday life, USA: Anchor Books.

9. Hathi, S., 2009. How social networking increases collaboration at IBM. Strategic Communication Management, 14(1), pp.32 - 35.

10. Ibarra, H., 1999. Provisional Selves: Experimenting with image and identity in professional adaptation. Administrative Science Quarterly, 44(4), pp.764.

11. King, N., 2004. Template analysis. In G. Cassell, C.M. and Symon, ed. Essential Guide to Qualitative Methods in Organizational Research. London: Sage Publications Ltd.

12. Klein, H. \& Myers, M., 1999. A set of principles for conducting and evaluating interpretive field studies in information systems. MIS Quarterly, 23(1), pp.67-93.

13. Lampinen, A., Tamminen, S. and Oulasvirta, A., 2009, May. All my people right here, right now: management of group co-presence on a social networking site. In Proceedings of the ACM 2009 international conference on supporting group work, pp. 281-290. ACM.

14. Leary, M. \& Allen, A., 2011. Self-presentational persona: Simultaneous management of multiple impressions. Journal of personality and social psychology, 101(5), pp.1033-1049.

15. Lee, A. S., 1991. Integrating positivist and interpretive approaches to organizational research. Organization Science 2(4), 342-365.

16. Lincoln, Y.S. \& Guba, E.G., 1985. Naturalistic inquiry., Beverly Hills, CA: Sage Publications.

17. Malaterre, A., Rothbard, N. \& Berg, J., 2012. When worlds collide in cyberspace: How boundary work in online social networks impacts professional relationships. Academy of Management Review.

18. Majchrzak, A., Cherbakov, L. \& Ives, B., 2009. Harnessing the power of the crowds with corporate social networking tools: How IBM does it. Management Information Systems Quarterly Executive, 8(2), pp.151-156.

19. Nilekani, N., 2009. Imagining India: The idea of a renewed nation., New York: Penguin Books.

20. Orlikowski, W.J., 2007. Sociomaterial practices: Exploring technology at work. Organization Studies, 28(9), pp.1435-1448.

21. Raghuram, S., 2013. Identities on call: Impact of impression management on Indian call center agents. Human Relations, 66(11), pp.1471-1496.

22. Ravishankar, M.N., Pan, S.L. \& Myers, M.D., 2012. Information technology offshoring in India: a postcolonial perspective. European Journal of Information Systems, (May 2011), pp.1-16.

23. Roberts, L.M., Dutton, J.E., Spreitzer, G.M., Heaphy, E.D. \& Quinn, R.E., 2005. Composing the reflected best-self portrait: Building pathways for becoming extraordinary in work organizations. Academy of Management Review, 30(4), pp.712. 
24. Sayah, S., 2013. Managing work-life boundaries with information and communication technologies. New Technology, Work and Employment, 28(3), pp.179-196.

25. Schoneboom, A., 2011. Workblogging in a Facebook age. Work, Employment \& Society, 25(1), pp.132-140.

26. Skeels, M. \& Grudin, J., 2009. When social networks cross boundaries : A case study of workplace use of Facebook and LinkedIn. In Proceedings of the ACM.

27. Strauss, A. and Corbin, J., 1990. Basics of qualitative research (Vol. 15). Newbury Park, CA: Sage.

28. Tufekci, Z., 2008. Grooming, gossip, Facebook and Myspace. Information, Communication \& Society, 11(4), pp.544-564.

29. Upadhya, C. \& Vasavi, A., 2006. Work, culture, and sociality in the Indian IT industry: A sociological study.

30. Utz, S., 2010. Show me your friends and I will tell you what type of person you are: How one's profile, number of friends, and type of friends influence impression formation on social network sites. Journal of Computer-Mediated Communication, 15(2), pp.314-335.

31. Vaast, E., 2007. Playing with masks: Fragmentation and continuity in the presentation of self in an occupational online forum. Information Technology \& People, 20(4), pp.334-351.

32. Vasalou, A., Joinson, A., Banziger, T., Goldie, P. \& Pitt, J., 2008. Avatars in social media: Balancing accuracy, playfulness and embodied messages. International Journal of HumanComputer Studies, 66(11), pp.801-811.

33. Veerapen, M., 2011. Encountering oneself and other: a case study of identity formation in second life. In A. Peachey \& M. Childs, eds. Reinventing Ourselves: Contemporary Concepts of Identity in Virtual Worlds. London: Springer London, pp. 81-100.

34. Zhao, S., Grasmuck, S. \& Martin, J., 2008. Identity construction on Facebook: Digital empowerment in anchored relationships. Computers in Human Behavior, 24(5), pp.18161836. 